\title{
Pulmonary rehabilitation in patients with interstitial lung disease associated with rheumatoid arthritis or connective tissue disease: From mechanisms to practice
}

\author{
Ioana RUSU ${ }^{1}$, Laura DAMIAN ${ }^{2,3}$, Daisy Ana-Maria VAIDA VOEVOD ${ }^{1}$, Romana VULTURAR ${ }^{4}$, \\ Laura MUNTEAN ${ }^{1,2}$, Simona REDNIC ${ }^{1,2}$ \\ ${ }^{1}$ Department of Rheumatology, "Iuliu Hatieganu" University of Medicine and Pharmacy, \\ Cluj-Napoca, Romania \\ ${ }^{2}$ Department of Rheumatology, Center for Rare Autoimmune and Autoinflammatory \\ Diseases, Emergency Clinical County Hospital Cluj, Cluj-Napoca, Romania \\ ${ }^{3} \mathrm{CMI}$ Reumatologie Dr. Damian, Cluj-Napoca, Romania \\ ${ }^{4}$ Department of Molecular Sciences, "Iuliu Hatieganu" University of Medicine and Pharmacy,
}

Cluj-Napoca, Romania

\begin{abstract}
Interstitial lung diseases are a large group of lung conditions characterized by inflammation and fibrosis. Interstitial lung disease in connective tissue diseases and rheumatoid arthritis is a severe complication of these pathologies. Apart from the pharmacological treatment, exercise training could help reduce breathing difficulties and increase physical strength, lower the burden of disease, help improving self-esteem and fight against depression and anxiety. Exercise training can be done either alone, or enhanced by auxiliary methods like oxygen administration, neuromuscular electrical stimulation or improving the strength of respiratory muscles. Possible associated lung diseases should be always taken into account. Even if exercise training is generally considered safe for this category of patients, there are also risks like exercise-induced hypoxemia, arrhythmia or pulmonary hypertension. Exercise training in this setting should be performed by dedicated physiotherapists after specialist prescription and under surveillance in a safe environment.
\end{abstract}

Keywords: connective tissue disease, interstitial lung disease, rheumatoid arthritis, interstitial lung disease, pulmonary rehabilitation, exercise training

\section{INTRODUCTION}

Interstitial lung diseases (ILD) are a large group of chronic lung conditions patophysiologically defined by chronic lung inflammation associated with scarring of the tissue. Consequently, these diseases are character- ized by a restrictive ventilatory pattern (1). Causes of ILD are diverse and include occupational exposure (e.g. asbestos), systemic diseases such as sarcoidosis, connective tissue diseases (CTDs) or rheumatoid arthritis (RA) or it can be idiopathic, such as idiopathic pulmonary fibrosis (IPF). The main types of pulmonary in- 
volvement in RA and CTDs are shown in Table 1, and their pathophysiological mechanisms are given in Figure 1. In genetically susceptible individuals, external factors such as infections, gastroesophageal reflux disease (GERD), smoking, environmental toxins, certain medication, can lead to epithelial cell injury and aberrant repair, alveolar macrophage activation, neutrophil recruitment, and oxidative stress. In this context of exposures, the host's immune tolerance is affected, leading to chronic inflammation (cellular and humoral autoimmunity). As the disease progresses, all these cellular processes eventually are ending in alveolar destruction, endothelial cell dysfunction, collagen deposition; over time, increased extracellular matrix turnover will result in the development of fibrosis.

Regardless of the underlying disease, ILDs are clinically characterized by dyspnea, shortness of breath, cough and exercise intolerance (2).

Even though ILD is a common complication of CTD and RA, there is little evidence of the role played by pulmonary rehabilitation in the recovery and the longterm outcome of RA-ILD or CTD-ILD respectively. Classically, it is believed that the same principles are applied as in IPF and chronic obstructive pulmonary disease (COPD) which are more largely studied (3). One systematic review on systemic sclerosis- associated ILD (SSc-ILD) has shown that although exercise training is considered generally safe, there are no definite conclusion on its efficacy (4). The aim of this review is to define the principles of rehabilitation in CTD-ILD and RAILD and to identify other needs that have not been previously addressed.

\section{AIMS OF REHABILITATION}

ILD is one of the leading causes of death in patients with CTD and RA, with variable severity, ranging from mild to severe in different patients (7). The main objectives of pulmonary rehabilitation is to "reduce breathing difficulties" and to "increase physical strength". In order to maintain these, pulmonary rehabilitation includes: aerobic exercise, maintaining the flexibility of the rib cage and the breathing muscles, lower body muscle training, learning breathing methods. On the other hand, it has been proven that anxiety and depression are a major component of the burden of dis-
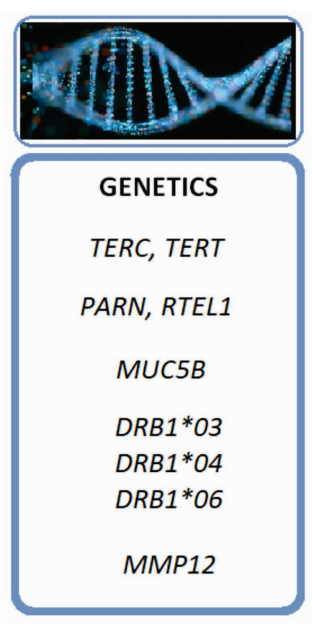

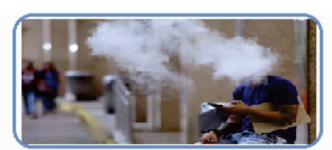

ENVIRONMENT Infections GERD Smoking Toxins Drugs Drugs
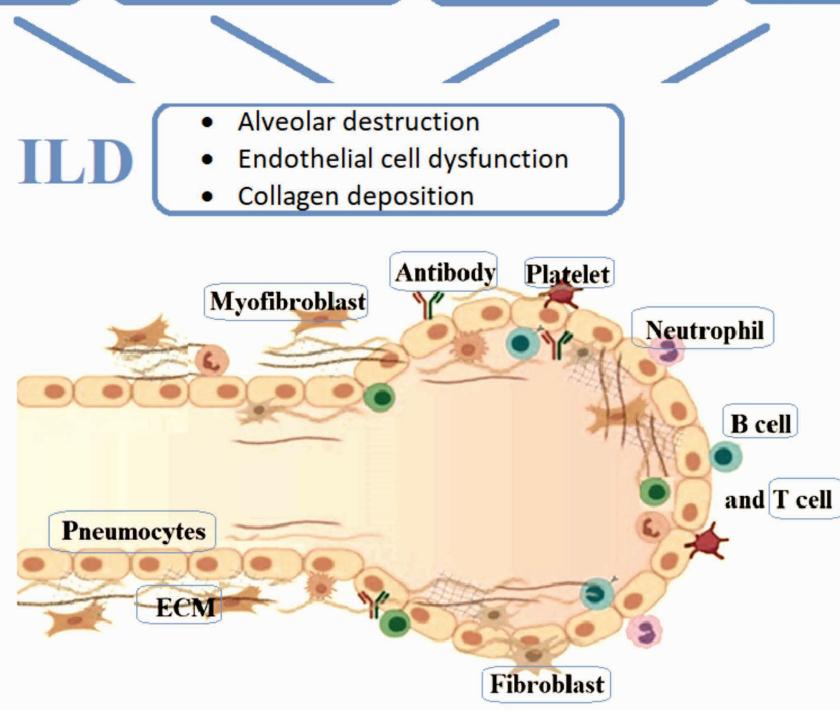

FIGURE 1. Representation of the main mechanisms and pathogenesis factors in the development of interstitial lung disease (ILD), adapted after (5)

ECM - Extracellular matrix; GERD - gastroesophageal reflux disease; ILD - interstitial lung disease; MMP12 - matrix metalloproteinases 12; MUC5B - recombinant mucin 5 subtype $B$; $M M P$ - matrix metalloproteinase 12; PARN - polyadenilation-specific ribonuclease deadenylation nuclease; $R O S$ - reactive oxygen species; RTEL1: telomere-elongation helicase-1; $T E R C$ - telomerase reverse transcriptase; TERT - telomerase reverse transcriptase 
TABLE 1. Types of lung involvement in rheumatoid arthritis and connective tissue diseases, adapted after (6)

\begin{tabular}{|l|l|l|}
\hline No. & Disease & Type of involvement \\
\hline 1. & RA & $\begin{array}{l}\text { ILD (mosty UIP) pulmonary nodules } \\
\text { Bronchitis/bronchiolitis } \\
\text { Pleuritis }\end{array}$ \\
\hline 2. & SLE & $\begin{array}{l}\text { ILD (mostly NSIP), OP, UIP, DAD } \\
\text { Alveolar haemorrhage } \\
\text { Pulmonary thromboembolism } \\
\text { PAH } \\
\text { Shrinking lung syndrome }\end{array}$ \\
\hline 3. & SSc & $\begin{array}{l}\text { ILD (mostly NSIP) } \\
\text { PAH } \\
\text { Aspiration pneumonia }\end{array}$ \\
\hline 4. & DM/PM & $\begin{array}{l}\text { ILD (mostly NSIP), OP, UIP, DAD } \\
\text { Respiratory muscle weakness }\end{array}$ \\
\hline 5. & MCTD & $\begin{array}{l}\text { ILD (mostly NSIP) } \\
\text { Respiratory muscle weakness } \\
\text { PAH } \\
\text { Aspiration pneumonia }\end{array}$ \\
\hline 6. & $\begin{array}{l}\text { Sjogren's } \\
\text { syndrome }\end{array}$ & $\begin{array}{l}\text { ILD (mostly UIP), lymphoid pneumonia } \\
\text { Bronchitis/bronchiolitis }\end{array}$ \\
\hline
\end{tabular}

SSc - systemic sclerosis; MCTD - mixed connective tissue disease; RA rheumatoid arthritis; DM/PM - dermatomyositis/ polymyositis; ILD - interstitial lung disease; NSIP - non-specific interstitial pneumonia; UIP usual interstitial pneumonia; $O P$ - organizing pneumonia; $D A D$ - diffuse alveolar damage; PAH - pulmonary arterial hypertension; PTE - pulmonary thromboembolism; ILD - interstitial lung disease

ease of these patients. Anxiety is present up to one third of the patients affected by ILD (8), and depression in up to a quarter of the patients, especially the ones with higher grade of dyspnea and more comorbidities (9). Therefore, improving the pulmonary status has a beneficial effect on the patients' well-being.

The patients suffering from ILD have a high exercise intolerance and a marked symptom burden. Apart from lung fibrosis, the skeletal muscle involvement and other types of respiratory complications (Table 1) also contribute to the burden of the disease and the effects on the quality of life. Therefore, by targeting these areas of interest, it is possible to preserve or regain exercise fitness and therefore to lower the incidence of depression, anxiety and fatigue (10).

\section{EXERCISE TRAINING}

Randomised controlled trials (RCT) have shown that full body exercise training is the main component of the pulmonary rehabilitation of patients with ILD. Pulmonary rehabilitation is achieved by conducting tolerance exercises that include walking, treadmill, elliptical training and cycling. On average, the training program lasts around 10 weeks and it includes at least $30 \mathrm{~min}$ of training in each session, with progression of the intensity on the course of the program. Both continuous, and interval training are effective (11).

Interval training consists of small period bursts of exercise followed by rest periods. It has been shown that interval training is as effective as continuous exercise as long as the total active period is the same (11). Some studies have shown that interval training is associated with lower exercise-induced dyspnea $(12,13)$ while others did not find a significant difference (14). One Cochrane review that included 9 RCTs whose main topic was ILD-related pulmonary rehabilitation showed that physical exercise in addition to pharmacological methods improved the distance at the 6 -minute walking test (6MWT) by 44 meters. Another study showed that the mean improvement of the 6MWT of patients with IPF undergoing physical exercise was $36 \mathrm{~m}$, which was significant because it exceeded the lowest important difference for this outcome $(15,16)$.

In patients who cannot tolerate full body exercise, partitioning of the active muscle mass could reduce the incidence of exercise-induced dyspnea and desaturation. In patients with COPD, cycling with only one leg at the same intensity as cycling with both legs is associated with an increased exercise peak power and higher $\mathrm{VO}_{2}(17-19)$

Lower 6MWT prior to the start of rehabilitation correlated to higher distance improvement in the end (20). Bigger improvements have been demonstrated in patients with higher forced vital capacity (FVC) at baseline, fewer episodes of desaturation and a smaller degree of disability at the beginning $(21,22)$.

\section{AIDING OF THE EXERCISE}

While for the most patients, physical training is a good option for improving pulmonary fitness, in patients with extensive pulmonary disease it is not possible. Therefore, there are a number of ways for aiding these patients.

In patients who suffer from exercise-induced dyspnea, severe and distressing symptoms like shortness of breath and cough could compromise the outcome of physical rehabilitation (3). Patients with extensive ILD or with a lower exercise tolerance may experience desaturation, especially during physical exercise, which results in suboptimal exercise training intensity. Oxygen administration during exercise could improve symptoms and training session outcome. Current guidelines state that supplemental oxygen should be administered to those patients who are bound to use ambulatory supplement oxygen (23). Taking into account that most patients with extensive ILD fulfill the criteria, many patients are eligible.

Neuromuscular electrical stimulation (NMES) uses intermittent electrical stimulation of one muscle group, most commonly quadriceps femoris, in order to achieve muscular training with little to no exercise- induced dyspnea (24). Supplementing exercise training with NEMS results in improved peripheral muscle tonus and 
lower respiratory burden (25). Therefore, NEMS is appropriate for very debilitated patients with little to no exercise ability.

One case study showed that improving the strength of respiratory muscles could help with the overall fitness (2). In order to achieve this, they used the BreathMaxÒ device and by performing upper limb elastic band exercises. The exercises were performed sitting on a chair or in bed by performing 4 sessions/day ( 2 sessions in the morning and 2 sessions in the afternoon) of 10 repetitions.

Although it has not been studied in ILD, in COPD water-based exercise is a good alternative to land-based training in patients with severe symptoms, comorbidities and especially in patients with musculoskeletal involvement (26).

\section{PATIENT SELECTION}

When it comes to patient selection for the pulmonary rehabilitation, there is little to no consensus. It was previously thought that rehabilitation may not be useful in patients with rapid evolving-ILD, considered to be associated with low quality of life and short life expectancy. However, more recent studies have shown that ILD has a variable clinical course with both periods of progression and some of stability (27). Therefore it was concluded that any patient diagnosed with ILD should start physical therapy as soon as possible.

\section{SAFETY AND LIMITATIONS}

Even though it is generally safe, there are no guidelines and no scientific papers to support the safety and the clear indications of performing pulmonary rehabilitation in CTD-ILD and RA-ILD. There is a major need for more RCT to evaluate the opportunity of exercise training in these patients. However, the lack of specialized physiotherapists, the lack of information on the rehabilitation of CTD and RA patients, as well as the scarcity of appropriate medical settings to do these kind of exercises, made difficult to complete such research. Therefore, physicians and physiotherapists are guiding their management on studies performed on COPD patients.

Exercise-induced hypoxemia is common in ILD, especially in patients with moderate to severe pulmonary fibrosis. In this regard, is commonly accepted that these patients should be consistently monitored during exercise by pulse-oximetry (28). Some patients presented cardiac arrythmias, especially atrial or ventricular premature contractions which appeared both during the 6MWT and at rest (29). Most of the time, these were not associated with desaturation and were asymptomatic (29).

In CTD-ILD and especially in patients with systemic sclerosis, pulmonary hypertension is a common complication of the disease. However, pulmonary hypertension can also be secondary to physical exercise. In a study performed in 2008 on 8 patients the mean systolic pulmonary pressure on echocardiography rose from $28 \mathrm{mmHg}$ at rest to $73 \mathrm{mmHg}$ during exercise (30).

All in all, even though there are little to no RCT to support the recommendation for physical rehabilitation, extrapolating its effect on COPD and IPF patients, we can generally consider that rehabilitation-associated risks are reduced, as long as it is performed by experienced physical therapists, in a safe environment such as a hospital facility. There are also risks like exercise-induced hypoxemia, arrhythmia or pulmonary hypertension. At the start of a physical training a thorough assessment of the disease complications (mainly cardiopulmonary, including 6MWT, pulmonary ventilatory tests- forced expiratory volume, diffusion of carbon monoxide, echocardiography with ejection fraction, pulmonary arterial pressure, and N-terminal pro-brain natriuretic peptide (NT-proBNP) and comorbidities (co-existence of osteo-articular, muscular, gastrointestinal complications and others). The exercise should be tailored and progress should be monitored and recorded using as much as possible validated scales. Physical training should not be undertaken during disease flares and in the presence of debilitating fatigue.

\section{CONCLUSIONS}

Even though there are no specific guidelines regarding the pulmonary rehabilitation in the treatment of patients with CTD-ILD and RA-ILD, there is no evidence to suggest that physical exercise has severe adverse effects on these patients, either. Moreover, physical exercise has been shown to improve symptomatology, lower the burden of disease, help improving self-esteem and fight against depression and anxiety. These findings suggest that the earlier a patient starts physical rehabilitation, the more results are seen in the long run.

Possible associated lung diseases should be always taken into account, and exercise training in this setting should be performed by dedicated physiotherapists after specialist prescription and under surveillance in a safe environment. Apart from improving aspects of the disease, physical rehabilitation helps patients integrate in a surrounding specially created for their needs, allowing them to take part in support groups. 


\section{REFERENCES}

1. Holland AE, Dowman LM, Hill CJ. Principles of rehabilitation and reactivation: Interstitial lung disease, sarcoidosis and rheumatoid disease with respiratory involvement. Respiration. 2015;89(2):89-99.

2. Leelarungrayub J, Pinkaew D, Wonglangka K, Eungpinichpong W, Klaphajone J. Short-Term Pulmonary Rehabilitation for a Female Patient with Chronic Scleroderma under a Single-Case Research Design. Clin Med Insights Circ Respir Pulm Med. 2016 Oct 4;10:11-17.

3. Bolton CE, Bevan-Smith EF, Blakey JD, Crowe P, et al.; British Thoracic Society Pulmonary Rehabilitation Guideline Development G; British Thoracic Society Standards of Care C: British Thoracic Society guideline on pulmonary rehabilitation in adults. Thorax 2013;68(suppl 2):ii1-ii30.

4. Liem SI, Vliet Vlieland TP, Schoones JW, de Vries-Bouwstra JK. The effect and safety of exercise therapy in patients with systemic sclerosis: A systematic review. Rheumatology Advances in Practice. 2019;3(2).

5. Shao T, Shi X, Yang S, Zhang W, Li X, Shu J, Alqalyoobi S, Zeki AA, Leung PS, Shuai Z. Interstitial Lung Disease in Connective Tissue Disease: A Common Lesion With Heterogeneous Mechanisms and Treatment Considerations. Front Immunol. 2021;12:684699.

6. Jee AS, Sheehy R, Hopkins P, Corte TJ, Grainge $C$, Troy LK, et al. Diagnosis and management of connective tissue disease-associated interstitial lung disease in Australia and New Zealand: A position statement from the Thoracic Society of Australia and New Zealand. Respirology. 2021;26(1):23-51.

7. Mugii N, Hamaguchi Y, Maddali-Bongi S. Clinical significance and usefulness of rehabilitation for systemic sclerosis. Journal of Scleroderma and Related Disorders. 2018;3(1):71-80.

8. Ryerson CJ, Hartman T, Elicker BM, Ley B, Lee JS, et al. Clinical features and outcomes in combined pulmonary fibrosis and emphysema in idiopathic pulmonary fibrosis. Chest. 2013;144:234-240.

9. Holland AE, Fiore JF Jr, Bell EC, Goh N, Westall G, et al. Dyspnoea and comorbidity contribute to anxiety and depression in interstitial lung disease. Respirology. 2014;19:1215-1221.

10. Swigris JJ, Fairclough DL, Morrison M, et al. Beneficial effects of pulmonary rehabilitation in idiopathic pulmonary fibrosis. Respir Care. 2011;56:783-789.

11. Beauchamp MK, Nonoyama M, Goldstein $\mathrm{RS}$, et al. Interval versus continuous training in individuals with chronic obstructive pulmonary disease - a systematic review. Thorax. 2010;65:157-164.

12. Vogiatzis I, Nanas S, Roussos C. Interval training as an alternative modality to continuous exercise in patients with COPD. Eur Respir J. 2002;20:12-19.

13. Vogiatzis I, Terzis G, Nanas S, Stratakos G, et al. Skeletal muscle adaptations to interval training in patients with advanced COPD. Chest. 2005;128:3838-3845.

14. Mador MJ, Krawza M, Alhajhusian A, Khan Al, Shaffer M, Kufel TJ. Interval training versus continuous training in patients with chronic obstructive pulmonary disease. $J$ Cardiopulm Rehabil Prev. 2009 MarApr;29(2):126-32.

15. Holland AE, Hill CJ, Conron M, Munro P, McDonald CF. Small changes in six-minute walk distance are important in diffuse parenchymal lung disease. Respir Med. 2009;103:1430-1435.

16. Dowman L, Hill CJ, Holland AE. Pulmonary rehabilitation for interstitial lung disease. Cochrane Database Syst Rev. 2014;10:CD006322.

17. Dolmage TE, Goldstein RS. Response to onelegged cycling in patients with COPD. Chest. 2006;129:325-332.

18. Dolmage TE, Goldstein RS: Effects of onelegged exercise training of patients with COPD. Chest. 2008;133:370-376.

19. Bjorgen S, Hoff J, Husby VS, Hoydal MA, Tjonna AE, et al. Aerobic high intensity one and two legs interval cycling in chronic obstructive pulmonary disease: the sum of the parts is greater than the whole. Eur J Appl Physiol. 2009;106:501-507.

20. Ryerson CJ, Cayou C, Topp F, Hilling L, et al. Pulmonary rehabilitation improves long-term outcomes in interstitial lung disease: a prospective cohort study. Respir Med. 2014;108:203-210.

21. Holland AE, Hill CJ, Glaspole I, Goh N, McDonald CF. Predictors of benefit following pulmonary rehabilitation for interstitial lung disease. Respir Med. 2012;106:429-435.

22. Kozu R, Jenkins S, Senjyu H. Effect of disability level on response to pulmonary rehabilitation in patients with idiopathic pulmonary fibrosis. Respirology. 2011;16:1196-1202.

23. Jenkins $S$, Cecins N. Six-minute walk test: observed adverse events and oxygen desaturation in a large cohort of patients with chronic lung disease. Intern Med J. 2011;41:416-422.

24. Zanotti E, Felicetti G, Maini M, Fracchia C. Peripheral muscle strength training in bedbound patients with COPD receiving mechanical ventilation: effect of electrical stimulation. Chest. 2003;124:292-296.

25. Vivodtzev I, Pepin JL, Vottero G, Mayer V, Porsin B, Levy P, Wuyam B. Improvement in quadriceps strength and dyspnea in daily tasks after 1 month of electrical stimulation in severely deconditioned and malnourished COPD. Chest. 2006;129:1540-1548.

26. McNamara RJ, McKeough ZJ, McKenzie $\mathrm{DK}$, Alison JA. Water-based exercise in COPD with physical comorbidities: a randomised controlled trial. Eur Respir J. 2013;41:1284-1291.

27. Raghu G, Collard HR, Egan JJ, Martinez FJ, et al. An official ATS/ERS/JRS/ALAT statement: idiopathic pulmonary fibrosis: evidencebased guidelines for diagnosis and management. Am J Respir Crit Care Med. 2011;183:788-824.

28. Spruit MA, Singh SJ, Garvey C, ZuWallack $\mathrm{R}$, Nici L, et al. An official American Thoracic Society/European Respiratory Society statement: key concepts and advances in pulmonary rehabilitation. Am J Respir Crit Care Med. 2013;188:e13-e64.

29. Park JH, Jegal Y, Shim TS, Lim CM, Lee SD, et al. Hypoxemia and arrhythmia during daily activities and six-minute walk test in fibrotic interstitial lung diseases. J Korean Med Sci. 2011;26:372-378.

30. Pouwels-Fry S, Pouwels S, Fournier C, Duchemin A, et al. Effects of oxygen on exercise-induced increase of pulmonary arterial pressure in idiopathic pulmonary fibrosis. Sarcoidosis Vasc Diffuse Lung Dis. 2008:25:133-139. 